\title{
STUDY OF ENGLISH SOUNDS: PHONETICS AND PHONOLOGY IN ACTION
}

Nick Ceramella*

Abstract. What justification might there be for an essay on phonetics and phonology? After all, there is already a plethora of books on the subject. However, most of them are highly academic in their approach, provide a detailed initiation into this particular area of language study and tend to be as technical as lengthy: Of course, they serve their purpose well, but can be daunting to the neophyte.

This essay then is meant to cover the need for a more general and gradual introduction to such a complex area of the study of English. I simply intend to supply a support to the more academically oriented introductions to phonetics, thus preparing the conceptual ground.

This is a summary overview of the main features of this area of linguistics: its scope and principles of enquiry, its key concepts and basic issues. These are expressed and explained in such a way to make them as accessible as possible to people who have no prior knowledge or expertise in the subject. Yet, allow me to say that however simple my approach may be, it is not simplistic. The idea is to give students an initial familiarity with the fascinating and challenging world of sounds "in action", and to encourage them into close critical exploration where the issues might not be readily accessible. Key words: Phonetic; Phonology; Pronunciation; Language acquisition; Language teaching; Morphology; Applied linguistics

\section{INTRODUCTION}

\subsection{LANGUAGE ACQUISITION}

The sounds of speech surround us - we hear and utter them - yet we know so little about them.

There are an unlimited number of speech sounds presenting minute phonetic differences which are way below the limit of perception.

The purpose of this essay is to focus our attention on how English sounds in particular are produced, and how they contribute to the process of communication, but before entering this intricate 'web' it will be useful to focus

\footnotetext{
Associate Professor of ESP of the Department of Media Studies, Arts Faculty, of the Jibera Unuersita Maria Santissima Assunta (LUMSA), Rome, Italy; Associnte Professor of Diachronic I listory of linglish and Varieties of Present-Day English of the Faculty of Forcign Modern Languages and Literatures, of the Universita degli Studi di Roma Tres, Italy; and of Translation Theory and Practice/ History of English, of the Department of Anglistics, Arts Faculty, Universita degli Study di Roma La Sapienza, ltaly:
} 
our attention on how a language is acquired. The first aspect to be underlined is that this is a specific characteristic of all human beings and no other animals. Actually, there is sufficient evidence to suggest that we are born with the predisposition to learn languages by the nature of our mental endowment (i.e. neurological factors) more than by the shape of our speech tract, a point which is further proved by the fact that we are the only 'animals' able to articulate words and consequently express thoughts. On the other hand, it is also true that animals have their own way of communicating among themselves, including the more intelligent ones, such as dolphins or chimpanzees which repeat the same signals (e. g. call of danger, mating availability), but unlike people they keep sending a limited number of messages. Unlike what happens with animals, there is continuous novelty with human beings as shown by the remarkable creativity and structural complexity of the messages that are uttered. We, as humans, can produce and understand an unlimited number of phrases which are never the same. Regardless of what most people think, it is highly improbable that a sentence is repeated exactly in the same way twice; talking is not imitating memorised sentences like a parrot. Even children, who seem to pick up their mother tongue by imitating adults and playing with other children, in actual fact create sentences quite spontaneously and autonomously without needing any tutoring. They are naturally endowed to learn any language and become a native speaker. Children may fail to learn maths, history, or swimming, but if they have no physical defects, they will certainly acquire at least their mother tongue. In effect, they can speak one or more languages in native fashion as long as they have a long enough exposure to them. By way of example, I would like to make reference to my grandson, Francesco, who at the age of two, even if he was not regularly exposed to English, but mainly Italian, used to show clear signs of learning new English words quite easily. Moreover, owing to the constant presence of his Ecuadorian nanny, he could understand Spanish too, while he was developing a Spanish accent when speaking Italian, and managed to keep the three language systems separate at a comprehension level. In comparison most of the students of English aged between 14-24, and over, whom I have taught through the years, have more often than not shown great difficulty in learning English as they got older, while gradually losing their natural ease in acquiring a second language, an asset which children are usually endowed with until the age of $10 / 11$. On the contrary, learning a foreign language for an adult is time consuming, takes a major effort and rarely results in mastery of the new system. This brings to mind another practical case I was personally a witness of, when I was teaching at the 'United World College of the Atlantic' in south 
Wales (UK), where a Spanish colleague of mine and his five children lived in that particular period. The astonishing thing with this family was that Pepe and his wife (in their late thirties at the time) spoke with a very heavy Spanish accent and had also great difficulty in understanding English, whereas their kids spoke it well. It was crystal clear that as the age of the speaker decreased, the quality of the language was nearer and nearer to the native Welsh accent. It is also worth of notice that the youngest children, who were four and six, could naturally switch from English to Spanish and vice versa by keeping the two systems separate, without showing any signs of a foreign accent in either case. On a comparative basis, the interesting point is that you could still detect a Spanish accent with their fifteen- and seventeen-year-old daughters, which was stronger with the elder one. The funny thing was that their parents spoke 'Espanglish', as Pepe ironically used to call it. This example confirms that, as has been proved by years of field research, the onset of adolescence seems to represent the dividing line in the ability to master a foreign linguistic system. To this day, an adequate and thorough account of language acquisition is still to be accomplished, although enormous progress has been made towards this aim.

\subsection{RANGE OF ACCENTS}

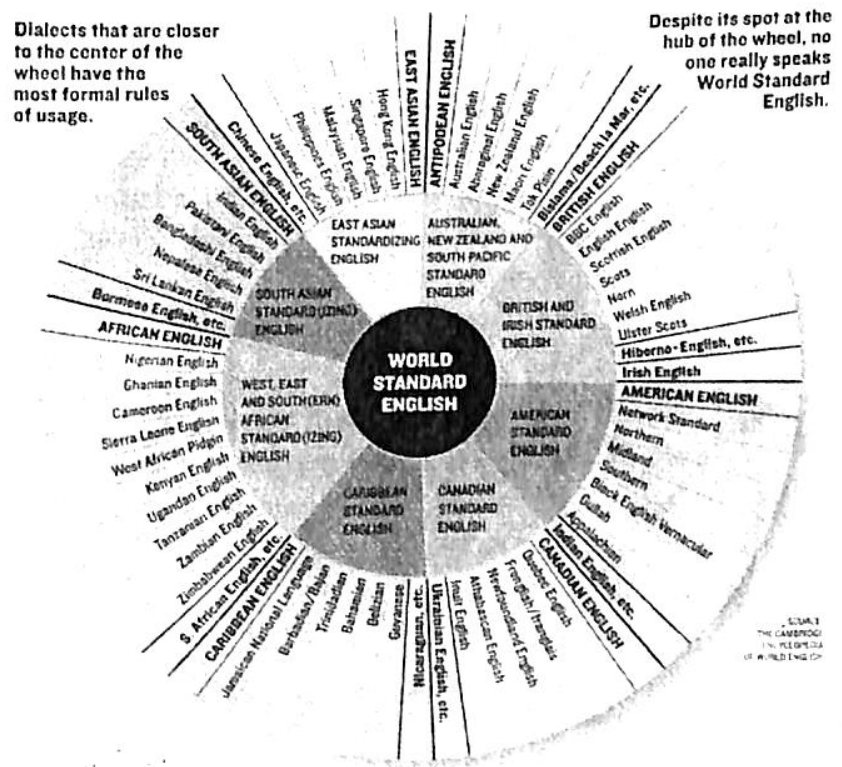

I"igure 1: The (ilobal I anguage in a (ircle (Source: The Cambridge lincyclopedia of World Iinglish) 
Another relevant aspect, worth bringing forth, concerns the different countries where English is spoken and the consequent wide variety of accents that developed in each of them. It goes without saying that this would take at least one essay apart to be covered adequately. Therefore. I will just try to give an overall view to put you in the picture.

When we come down to experience we find that the written form of a language is more often than not homogeneous all over the region where it is used, while the spoken form tends to differ from area to area. As far as English is concerned, there are a number of widely accepted accents going from American (which varies greatly in its different forms East, South, Mid-West, and West) to Canadian, Australian, and New Zealander, besides the English used in the emerging former British colonies, South Africa, India, Nigeria, West Indies, just to mention the main ones.

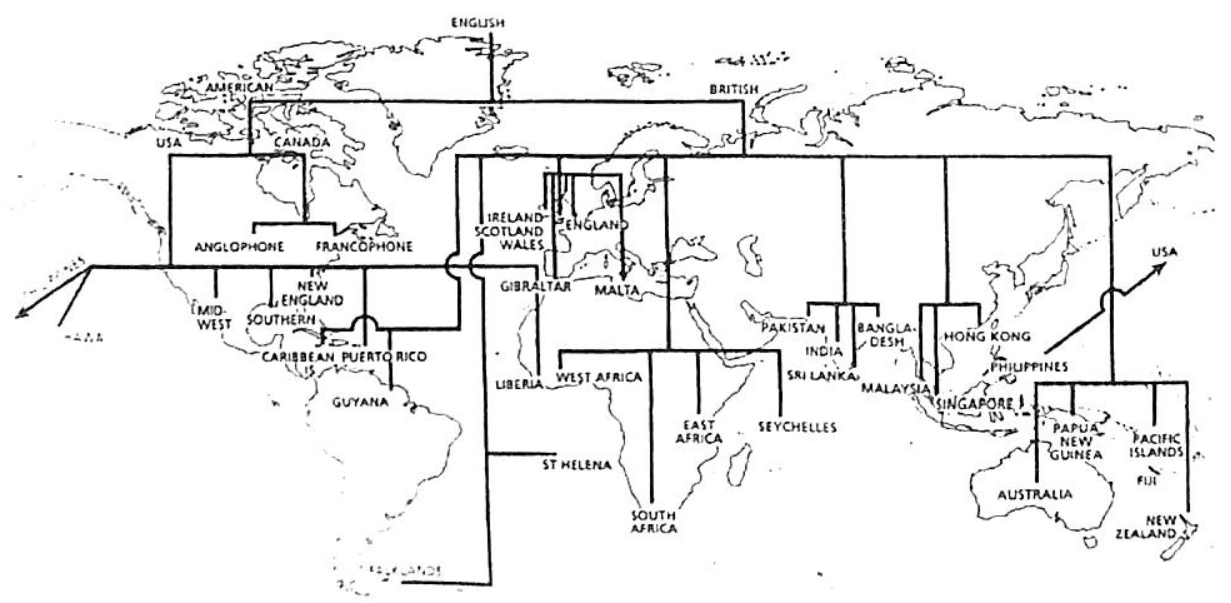

Jigure 2. Tamily trec representation of how Iinglish has spread around the workd. (I rom D). (Crystal, English as a Global Langurage).

However, here I intend to draw your attention to what I am more familiar with, the accents employed on the British Isles only. I will start from Standard English, associated with the so-called Home Counties, that is the six counties in the London area, urban districts, parts of Wales and western Cornwall where English, due to the use of Celtic languages, was introduced fairly recently. Standard English is one of the main modern dialectswhich, as opposed to the traditional dialects, are usually spoken by the middle- and upper-class layer of society as well as by younger people. 


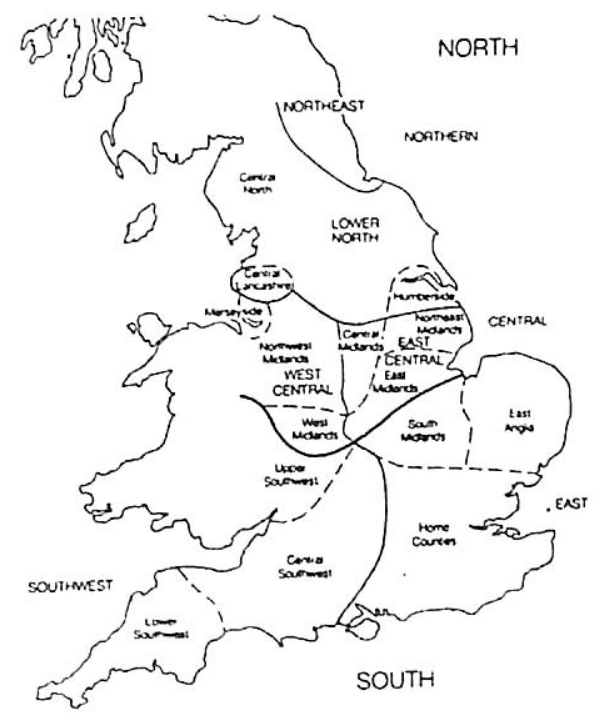

I"igure 3: Modern dialect division Source: 1?. Trudgill, Accent, Dialect and the School, 1,ondon: Fidward Arnold, 1978, 63)

This strong distinction between dialects, a key feature of the history of the English language, made George Bernard Shaw say, "It is impossible for an Englishman to open his mouth without making some other Englishman despise him." As a matter of fact, language standardization did not appear until Queen Victoria's reign when the notion of Queen's English was first introduced. Then, due to the 1870 Education Act, which established a compulsory national school system at the elementary level, a social accent, Received Pronunciation, known as RP, emerged and became the typical pronunciation of educated people, like upper ranks of the army, the clergy and the Imperial Civil Servicemen. Finally, as recently as 1984, the phonetician David Rosewarne coined a new term Estuary English to define a variety of today's English, lying between RP/Queen's English and the south eastern pronunciation/London's Cockney.

On considering the situation outside England, the main striking thing is that in Scotland, Ireland and Wales, English sounds like a 'foreign' language. This happens because it is marked by the interference of the native languages, Gaelic, in Scotland and Ireland (with its two different varieties) and Welsh, in Wales.

In Scotland, a dialect of English, called Siottisin the fifteenth century, developed into a new language in its own right, Scots, which due to radical 
political changes was subject to ups and downs and gradually gave way to Standard English. However, Scots, although by a minority, has continued to be spoken; so, following the 1999 referendum in favour of devolution, through which Scotland gained back its autonomy, the nationalist movement has been encouraged to support ever since the wish to turn it into the national language of the country.

In Wales, the presence of English dates back to the twelfth century when Henry I established an English-Flemish settlement in Pembrokeshire, followed by the anglicization of the Gower peninsula by the fourteenth century. The rest of the region remained a Welsh-speaking area until the Acts of Union in 1536 and 1542 imposed that only English should be used in legal and administrative matters and that no one other than English speakers could take any posts under the Crown. Welsh continued to be used by the Church and even increased its importance when the Bible was translated from English in 1563. A terrible blow to the use of Welsh came with the Education Act of 1881 which required English as the only language to be taught in primary education. No wonder if by 1981 the number of monolingual English-speakers reached 81 per cent of the total population, that is to say that only 800,000 people are bilingual today, notwithstanding the efforts made to keep Welsh alive by the $\mathrm{BBC}$ regional services broadcasting many hours in the native language, and the promotion and courses organised by the Welshlanguage societies. Here, like in Scotland, it is very much up to the speakers to keep their native language alive, the more they use it the higher are the chances that it will survive.

In Ireland, Irish Gaelic has traditionally been identified with Catholicism and opposed to English, the language of the Protestant invaders. in Ireland:

There are three historical periods when English had a major influence

a) 1171-1578, resulting in no impact on the native language;

b) seventeenth and eighteenth century, confirming the religious connotation of the issue at stake, but this time English gradually became the language of the towns, whereas Irish Gaelic was used in the countryside;

c) in 1801 , the Act of Union included Ireland as a member country of the United Kingdom and using English was viewed as a must if one wanted to have a career and be considered caring for the progress of Ireland. Then, in the twentieth century, writing in the so-called Hiberno-English (opposed to the Rural version more characterised 
by a Gaelic influence) has become a real literary language thanks to great authors like J. P. Synge, Sean O'Casey and William Butler Yeats in the early decades of the century.

Today there are just 100,000 Irish who can speak their mother tongue.

In Northern Ireland, by contrast, there is a clear cut distinction between Northern and Southern Hiberno-English in Northern Ireland. But in the extreme North, they employ the so-called Ulster Scots, the language used by the poet Robert Burns (1759-96), supported by the tradition of attending Scottish universities, while in the West the major influence is clearly Irish.

At this point, an obvious conclusion that can be easily drawn is that all these accents, and, mind you, we have only taken into account Britain and Ireland, represent a major problem for the teachers of English. In fact, which accent should they choose to teach? In my view, they should pick one only and stick to it, perhaps British Standard English, if for no other reason, because it all began in England and, even more important, because it is the most known and used form, hence it is very useful to know on applying for a job. Having said that, I would like to stress that exposing one's students to a variety of accents (e.g. American Standard English) by using recordings without recommending any one in particular, cannot but have a positive effect on their overall knowledge of the language.

And now we are ready to tackle and analyse the key theme of this essay: the study of the English sound system.

\subsection{WHAT SHOULD COME FIRST?}

A language description concerns phonetics, grammar, vocabulary and meaning. Each of these areas has its own peculiarities of method and content. A legitimate question then is whether the phonological system should be taught before getting at grammar and vocabulary. In other words, should students learn the sound, rhythm and intonation systems of the language first? Experiments in this sense, such as that carried out by Morton in 1965, who dedicated the first 300 hours of a language course to what he called 'acoustic grammar', proved to be a catastrophic experience, lowering the students' motivation way down to the dregs. In 1964, L. Newmark declared:

to teach the sound systems of the language before the grammar and the vocabulary is not in good agreement with our common sense, feeling that it is more important to be able to speak a language fluently and say a lot of things in it than to have a marvellous pronunciation but 
not know what to say.

(Grammatical Theory and the Teaching of English, NAFSA Papers, no. 9, 1964, p. 7).

Whoever teaches a language knows from experience that linguistic and pedagogical reasons indicate that grammar, vocabulary and pronunciation teaching should proceed side by side within a parallel syllabus; here we distinguish the meanings of words, the sound sequences corresponding to these meanings, and the ways in which words connect with one another to form sentences. That's why I agree with Ronald W. Langacker saying, "A language is a device that establishes sound-meaning correlations, pairing meanings with signals to enable people to exchange ideas via observable sequences of sounds." (Langurge and its Structure, N.Y.: Harcourt, Brace \& World, p. 24).

\subsection{TEACHING PRONUNCIATION}

Pronunciation is in itself the conversion into audible sounds of what has been learnt in silence (i.e. grammar, syntax, vocabulary). It involves not only a mental activity but also a motor one, thus resembling more gymustia than linguistics. If learners, generally speaking, have different language learning ability levels, when studying pronunciation this difference is even more marked by age and a good ear.

As we get older, we tend to reduce our ability to learn a language, including the pronunciation area:

- our ability to hear and distinguish sounds decreases;

- we tend to pay more attention to what we say than how we say it, which turns into a disadvantage when you are trying to learn a foreign language as an adult. Actually, the older you are and the more your ability to mimic any speech diminishes;

- we get increasingly shier and do not like to be 'laughed' at for our mistakes that anybody can hear, which is why adults prefer writing to speaking when studying a foreign language.

But there is a counterbalance to all that: adults have acquired the ability and patience to learn through their lives and can be exposed to longer practice session without easily losing their concentration.

The possession of a good ear is certainly an advantage and you are usually born with it, which allows you to imitate pronunciation with an above average accuracy. However, as a learner grows older s/he gradually loses the power of mimicry, declining from about $80 \%$ at the age of 10 to $70 \%$ at 25 . 
All the disadvantages above, that increase with age, can be taken care of by getting learners to familiarise themselves with phonetics, phonology and speech training. They need to become aware of what pronunciation is all about. But let's face it, if teaching is an art in its own right, pronunciation teaching is an even more special category of language teaching, requiring cerebral and physical training, two features that are surely not common among average teachers.

\section{PHONETICS}

Until 1928, when the First International Linguistic Conference was held at Den Hague in Holland, phonetics was considered as the only science dealing with the physical aspects of a language. While today, to say it with $L$. Kaiser it represents the 'cement' linking the various elements making up the study of a language. It is widely agreed that a language is a system of signs, that is to say some kind of code based on a set of invariable symbols. For instance, if we take the English word fig, we note that from a phonetic point of view it consists of three symbols or segments /f/, / / , and /g/. Indeed, phonetics describes and studies this code, but it is also the science focusing on the analysis of the sounds of human speech.

Phonetics as such develops into three different branches: articulatory-describing sounds in terms of the way speech-organs (vocal cords, tongue, lips, teeth, nose, larynx, etc.) produce them;

acoustic-considering the acoustic waves going from the speaker to the hearer; auditory-treating the physical effects acoustic waves have on the hearer, perhaps the least developed area to this day.

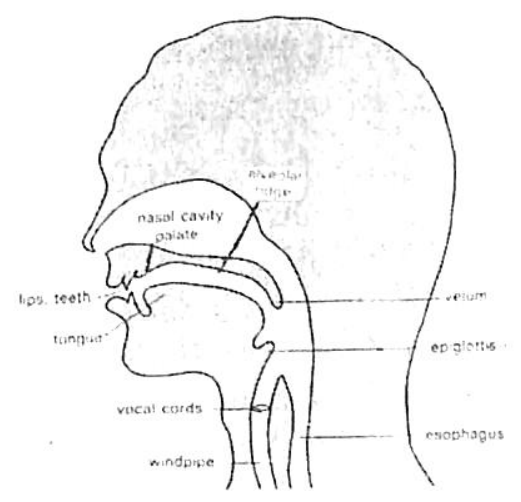

Figure 4: Speech tract (Source: D. O'Connor, Phonetics, Harmondsworth: Penguin, 1982, 143) 


\subsection{ARTICULATORY PHONETICS}

Phoneticians treat "sounds" as mere physical entities, regardless of what language they belong to, or as "functional sounds", that is "relevant for the purpose of communication". In the former case, a phonetician will come out with a phonetic description of what is uttered, in the latter, $s /$ he will give a phonological description. On proceeding, it is worth remarking that there are no two people who sound exactly the same, as proved by our ability to identify all the people we know just on hearing them say 'hello' on the phone, but, as already hinted at above, we must also remember that the same person never utters the same word in a physically identical way on separate occasions. The difference may concern the length of a single phoneme such as $/ \mathrm{h} /$ in a word like 'hello' itself, where it may be a few milliseconds longer from time to time it is uttered. We are obviously not talking about semantic substance but just principle.

Within the range of articulatory phonetics there are three aspects which represent the core object of its research activity: voice and pitch, hence, vowel and consonant articulation.

\section{- Voice and pitch}

The voice is produced by the innate ability to make sounds on speaking through the regular vibration of the vocal cords. The degree of highness or lowness of a voice (pitch) depends on how tensed the cords are on vibrating. These speech-sounds are divided into two categories: vonvels and consonants. The former are voiced sounds (so-called because when articulated there is no obstruction wherever in the speech-organs, so the air passes through freely), the latter are-mixed, voiced and unvoiced.

\section{- Vonel Articulation}

The vibration of the vocal cords (two elastic thin bands of membranes inside the little box known as "Adam's apple"), called voicing, generates the vowel sounds resulting from the unobstructed outflow of air. Besides the vocal cords, a key role in the articulation of vowel sounds is played by the tongue, lips, and the velum (the soft rear part of the roof of the mouth). The changing posture of these organs determines the distribution of energy over the frequency spectrum which we perceive as differences in vowel quality. Vowels are usually classified according to Daniel Jones's system, taking into consideration as he himself declares: "a set of fixed vowel-sounds having known acoustic qualities and known 
tongue and lip positions". These so-called 'cardinal' vowels are produced by the

- position of the lips

(rounded v. spread, or unrounded),

- opening degree of the mouth [i.e. velum] (close v. open),

- position of the highest part of the tongue (front $\mathrm{v}$. back).

The lips have many degrees of movement and assume various shapes which determine the quality of the vowel sounds, as shown in the figure below. Close-rounding as in 'wool', open rounding as in 'hog', spreading as in 'tea', and neutral as in 'ah'.
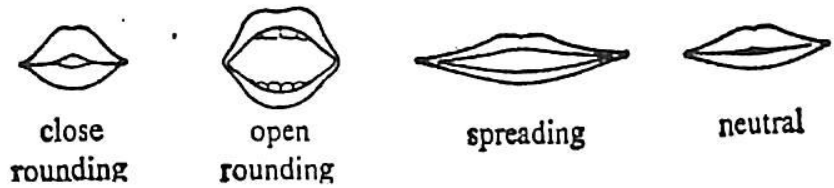

Figure 5 : Lip positions (Source: J. D. O'Connor, Phonetics, Harmondsworth: Penguin, 1982, 37)

The degree of lowering of the velum modifies the sound of vowels. If the air is let through the nasal cavity we produce nasal vowels, which are not used in English, while those articulated with the velum closed are called oral.

We generally talk about the position of the tongue with reference to two positions, high-low and front-back. This means that the tongue may be stretched up towards the palate, or it may be held low, producing high and low vowel sounds. Accordingly, as you can see in the figure below, [a] in mother is a low vowel, [u] and book, and [i] in teeth are high.

The position of the tongue during the articulation of various vowel sounds is shown by the figure below. As you can see, a vowel can have an intermediate (mid) height between high and low. Starting from [i] down to [æ], one can utter all the intermediate sounds in a vertical line of descent by lowering both tongue and jaw. Similarly, it is possible to go from [u] to [a]. Alternatively, a vowel can be intermediate in the front-back area, ranging from front vowels such as [i] to back ones like $[\mathrm{u}]$, where it is interesting to note that the height of the tongue is more or less comparable, just as it is with the other pairs appearing in each section in a horizontal line. 


\begin{tabular}{|c|c|c|c|}
\hline & FRONT & CENTRAL & $\mathrm{BACK}$ \\
\hline $\mathrm{HIGH}$ & $\begin{array}{l}\text { [i:] beat } \\
\text { [i] bit }\end{array}$ & & $\begin{array}{l}\text { cooed [u:] } \\
\text { could }[\mathrm{U}]\end{array}$ \\
\hline MID & $\begin{array}{l}\text { [ei] bait } \\
\text { [e] bet }\end{array}$ & $\begin{array}{l}{[\supset U]} \\
\text { roses }\end{array}$ & $\begin{array}{l}\text { code }[\partial u] \\
\text { cawed }[\supset:]\end{array}$ \\
\hline LOIV & $\begin{array}{l}{[æ]} \\
\text { bat }\end{array}$ & $\begin{array}{l}{[\Lambda]} \\
\text { but }\end{array}$ & $\operatorname{cod}[\mathrm{D}]$ \\
\hline
\end{tabular}

Fïgure 6: l'osition of tongue on articulating vowel sounds

Now I would like to draw your attention to the figure below, where you can see the indications of the usual tongue positions for the vowels as pronounced in the Anglophone speaking-world, let alone the many other variations present also in countries where English is widely offered at schools and universities, and where, uttering certain English vowel sounds can be a problem. As an Italian, and a teacher of English, I know this is the case with the average Italian learner of this language. A remarkable instance is represented by the tendency to simplify the pronunciation of the English vowel / a / as / e/ (cf. the Italian word 'teste' [heads]), while curiously enough / a / in Italian is always pronounced as in pasta, unless we consider a regional dialect such as Apulian, where, for example Bari (the main city in the Apulia region) is pronounced Beri. So, in Italy, you can invariably hear words like bad sounding like bed, or man like men, regardless of the consequent nullification of the semantic differences within each pair. The first explanation to this may be that the exact pronunciation of $/ \mathrm{a} /$ in these two words is $/ \mathrm{x} /$, which has no equivalent in Italian. Yet, I still cannot see why they get it wrong, since as it is clearly visually shown also by the symbol $/ x /$, there is an $/ a /$ developing into an /e/ and not vice versa. The mistake finds no justification in the interference of the Italian language itself, I am afraid then the fault lies at the source which is not difficult to identify, is it?

The sounding quality of many vowels changes according to whether they occur in stressed or unstressed syllables. By way of example, in the question "Do you always do your exercises?" the first do contains a weak vowel form /o/, called schus (representing a typical English and French vowel reduction), while the second do contains a strong one $/ u: /$. 


\begin{tabular}{|c|c|c|c|c|}
\hline & Pure Vowel (V) & $V+j$ & $v+w$ & $\mathrm{~V}+\mathrm{h}$ \\
\hline |i/ & sit & see & new & near \\
\hline$(t)$ & sugar & see & moon & fur \\
\hline $\mid u /$ & put & buoy & do & boor \\
\hline$|e|$ & set & $\mathrm{saj}^{\prime}$ & house & fair \\
\hline$|0|$ & pump & bird & go & fur \\
\hline 101 & obey & boy & go & - paw \\
\hline$|æ|$ & pan & pass & house & bar \\
\hline$|a|$ & pawn & buy & house & psalm \\
\hline 101 & got & wash & law & paw \\
\hline
\end{tabular}

Figure 7: English vowel nuclei (Source: Langnage Teaching Analysis, William I:

Mackey, london: Longman, 1981, 57)

\section{- Consonant Articulation}

The mechanisms involved to produce articulate consonant sounds can be rather complex. Since this is only an article and not a whole book on phonetics, I have had to take a selective approach. Nevertheless, it is worth stressing that part of learning English involves, mastering the system of distinctive oppositions used in this language to differentiate morphemes, that is vowels and consonants. Of course, the speaker has to assimilate the phonological representations of each morpheme, a necessary information enabling him/her to pronounce them correctly.

Consonants are divided into voiced or voiceless, oral and nasal.

- We produce voiced consonants when the vocal cords continue to vibrate, as for instance [b] in bebop (a voiced bilabial stop); [d] as in $d u b$ (a voiced alveolar stop); [g] as in gig (a voiced velar stop).

- We produce voiceless consonants if the vocal cords stop vibrating and there is an emission of a puff of air as the closure ends, as is the case with $[\mathrm{p}, \mathrm{t}, \mathrm{k}]$ which are the counterparts of $[\mathrm{b}, \mathrm{d}, \mathrm{g}]$. 
- We talk about stops (or plosives), the most important consonants, if the air passage is completely obstructed [p]. If the blockage is partial, but produces friction, the resulting sounds are called fricatives (or spirants), perceived as a kind of hissing. The very part where the obstruction takes place is the point of articulation and may be the lips, the teeth ridge (or alveolar), the soft palate (or velum), or the hard palate.

It seems that the main articulator, they more often than not come in contact with, is the tongue, consisting of four parts: the apex (or tip), the dorsum (or back), the blade, and the middle. When the tip plays the role of articulator the result is the production of apical consonants, so, similarly, we make dorsal consonants when the articulator is the back of the tongue.

- Stops articulated with the tongue are called dental, alveolar, palatal, or velar. Like stops, fricatives can be identified by the point where the narrowest constriction is made. Therefore, if the stoppage is made with the upper teeth placed on the lower lip, we produce $[\mathrm{f}]$ a labio-dental fricative as in cliff.

$[\theta]$, as in thing, is a dental fricative, produced with the upper tongue making contact with the upper teeth; [s], occurring twice in sister, is an alveolar, while articulated a little more back on the tongue and just behind the alveolar ridge, is the palatal fricative [ $\int$ ] as in dish. If the stoppage is made with the vocal cords, we have a glottal fricative [h] as in hope. All these fricatives are voiceless, and except for $[\mathrm{h}]$, they all match witch the following series of voiced fricatives in point of articulation: $[\mathrm{v}, \delta, z, 3]$, which are the first consonants of veal, the, zip, and pleasure respectively.

- Another mode of consonant articulation combines the features of stops and fricatives. There are two of these sounds in the English language and are called affricates. For instance, see $\left[\mathrm{t} \int\right]$ in church, where it is a voiceless palatal affricate, as opposed to its counterpart [d3], illustrated twice in judge in which it is a voiced palatal affricate.

- The nasal consonants are produced by closing the mouth while lowering the soft palate to let air pass through the nasal cavity. These consonants are usually voiced but not necessarily always. They can be distinguished among them by the point where the 
oral closure is made. For English [m] as in men, the two lips are brought together, resulting in a bilabial nasal, while $[\mathrm{n}]$ in $n o$, is an alveolar nasal. The word song, despite the spelling, ends phonetically in one consonant only, a velar nasal, which is symbolised as [y].

- Now, we can deal with the liquids, the [l] and $[\mathrm{r}]$ sounds.

The various [1] sounds, known as laterals, are voiced in English. This name derives from the fact that, while the tongue makes an alveolar closure in the centre of the mouth, air is not really completely blocked and is allowed to come out on the sides (e.g. lad).

The $[\mathrm{r}]$, as in road, is uttered with no closure sounding like a vowel. This special character is given by the shape of the tongue whose front or rear is raised a little bit towards the roof of the mouth in a way that its upper surface is shaped like a cup.

- Finally, there are [w] and [y], the glides or semivonels, so-called because of their close relation to the vowels [u] and [i] respectively. If we take words like wow or wound and yoy, we can note that in both cases the vocal organs glide from their initial sounds to [a] and [o] and quickly back. (See also Linking section below). 


\begin{tabular}{|c|c|c|c|c|c|c|c|c|}
\hline & \multicolumn{4}{|c|}{ stop } & \multirow{2}{*}{\multicolumn{2}{|c|}{ fricative }} & \multirow[b]{2}{*}{ lateral } & \multirow{2}{*}{$\begin{array}{l}\text { frictionless } \\
\text { continuant }\end{array}$} \\
\hline & plo & ive & nasal & roll flap & & & & \\
\hline glottal & ? & & & & $\mathrm{h}$ & f & & \\
\hline pharyngal & & & & & $\hbar$ & ६ & & \\
\hline uvular & $\mathrm{q}$ & $G$ & $N N$ & $\mathrm{R} \quad \mathrm{R} R \mathrm{R}$ & $x$ & B & & ६ \\
\hline velar & $\mathrm{k}$ & $\mathrm{g}$ & ì $\eta$ & & $x$ & $\gamma$ & & $\gamma$ \\
\hline palatal & $\mathrm{c}$ & 3 & ก̊n & & q & $\mathrm{J}$ & $\kappa$ & $j$ \\
\hline retroflex & $t$ & $\mathrm{~d}$ & r $n$ & $\dot{r} \mathbf{r} \quad \dot{c} \tau$ & \$ & $z$ & 1 & $t$ \\
\hline post-alveolar & $t$ & d & $\dot{0} 0$ & $1 \leq 11$ & 1 & 1 & $!$ & $t$ \\
\hline alveolar & $t$ & $\mathrm{~d}$ & $n \mathrm{n}$ & r r r & $\mathrm{s}$ & $z$ & 11 & $z$ \\
\hline dental & $t$ & d & Dn & & 0 & $\delta$ & 1 & $\varnothing$ \\
\hline labio-dental & $\pi$ & $b$ & h⿱㇒冋 $\mathrm{m}$ & & $\mathrm{f}$ & $\mathrm{v}$ & & v \\
\hline bilabial & $\mathrm{p}$ & $\mathrm{b}$ & $\mathrm{m} \mathrm{m}$ & & $\Phi$ & $\beta$ & & $\beta$ \\
\hline
\end{tabular}

Notes

1. [6] indicates breathy vibration of vocal cords (p. 28): this occurs between vowels for English $h$ in e.g. behind.

2. For pre-velar and pre-palatal sounds the sign [ +] may be placed ahove or below the appropriate letter, e.g. [k] as in English key. And the sign [-] may be used similarly to indicate post-velar and post-palatal sounds, e.g. [ḡ] in English got.

3. [b] is a non-IPA symbol for the sound which may occur for $b$ in English obvious.

4. The gaps in the table are due mainly to the impossibility of combining a particular manner and a particular place, e.g. glottal nasal and palatal roll. and sometimes to the non-occurrence of a possible sound, e.g. a bilabial lateral. If any such sound needed a symbol, one would be provided al hoc. There are no voiceless frictionless continuants because this would imply silence; the voiceless counterpart of the frictionless continuant is the voiceless fricative.

Figure 8: Tables of consonants (Source: J. D. O'Connor, Phonetics, Harmondsworth: Penguin, 1982, 61)

\subsection{ACOUSTIC/AUDITORY PHONETICS}

In acoustic phonetics, we find that speaker ('transmitter') and hearer ('receiver'), during their communicative interaction, function both ways all the time. In brief, while speaking we do not only resource to our speaking system but also to our listening one, however unconsciously this may happen. Actually, there is a continuous registering and interpreting of the sounds as they are perceived which allows a fluent communication. This is to be meant not only as a physical activity but also as a psychological one, involving expectancies suggested by the situation and, of course, also by the sharing of the same grammatical and phonological structures. 
On concluding this very short subsection, it will surely deserve your attention to learn that not every single vibration on the tympanums is perceived by the human brain. Adults can hear sounds within a frequency ranging from \pm 20 vibrations, or sound waves (low frequency), to \pm 20.000 (high frequency) per second.

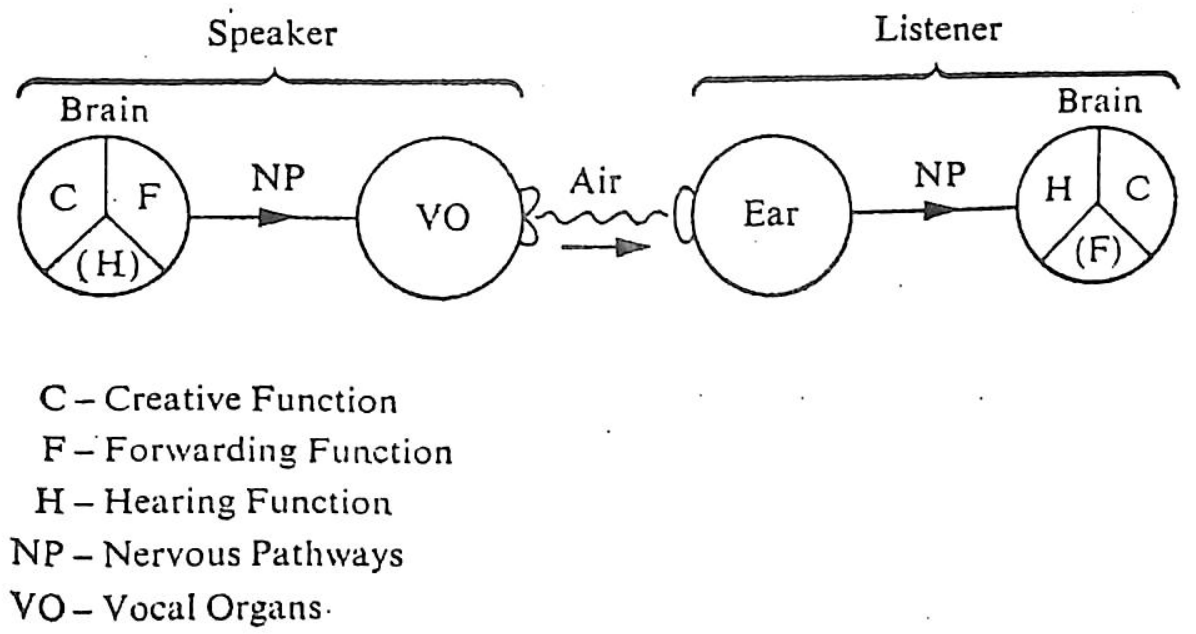

[ïigure 9: Stages in the passing of a spoken message (Source: J. D. O'Connor, Phonetics, Harmondsworth: Penguin, 1982, 37)

\subsection{PHONETIC ALPHABETS}

The International Phonetic Alphabet (IPA), which is based on the Roman alphabet, fixed the phonetic values of the letters corresponding to the main European languages. Two symbols were borrowed from the Greek alphabet $[\theta]$ and $[\delta]$ to represent the sound of $/ t h /$ in the words thought and that respectively. But however ingenious the IPA may be, it has its inconsistencies and limits. Therefore, some specific symbols had to be created purposely to represent certain sounds which could not be synthesised by one of the existing symbols only, as for example $\left[\mathrm{t} \int\right]$ in iburch or $[\mathrm{d} z]$ in judge.

Similarly, diacritics (marks placed over, through, or under a letter, to show a sound value different from that of the same letter without the mark, frequently used in some languages) had to be created to indicate what the IPA conventions consider as 'abnormal' pronunciation, or to give a 'narrower' transcription such as that of nasal sounds or short and long ones, which are 
indicated by /:/ immediately after a vowel. For your knowledge, besides the IPA there are other alphabets which are used especially in America, owing to the advantage represented by the possibility of typing them either on a normal typewriter or a computer.

\begin{tabular}{|c|c|c|c|c|}
\hline \multicolumn{2}{|c|}{ consonants } & \multicolumn{3}{|l|}{ vowels } \\
\hline symbol & examplo word & symbol & example & word \\
\hline b & back & is & sheep & \\
\hline d & day & 1 & ship & \\
\hline 0 & then & $\mathbf{i}$ & happy & \\
\hline d3 & jump & c & bed & \\
\hline f & fat & $\boldsymbol{x}$ & bad & \\
\hline $\mathrm{g}$ & get & a: & calm & \\
\hline h & hot & 0 & pot & \\
\hline j & yell & $x$ & caught & \\
\hline$k$ & key & $u$ & put & \\
\hline 1 & led & u & actuality & \\
\hline m & sum & u: & boot & \\
\hline$n$ & sun & $\hat{\jmath}$ & curt & \\
\hline$n$ & sung & $x$ & bird & \\
\hline $\mathrm{P}$ & pen & 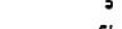 & cupboard & \\
\hline $\mathrm{r}$ & red & ci & make & \\
\hline s & $\begin{array}{l}\text { soon } \\
\text { fishing }\end{array}$ & $a_{1}^{\infty}$ & $\begin{array}{l}\text { note } \\
\text { blte }\end{array}$ & \\
\hline 1 & tea & av & now & \\
\hline If & cheer & x & boy & \\
\hline$\theta$ & thing & 12 & here & \\
\hline$v$ & view & is & peculiar & \\
\hline$w$ & wet & ea & there & \\
\hline$x$ & loch & כט & poor & \\
\hline$z$ & zero & us & ritual & \\
\hline 3 & pleasure & eID & player & $\cdot$ \\
\hline & & 200 & lower & \\
\hline & & כuכ & towar & \\
\hline & & כו כו & employer & \\
\hline
\end{tabular}

$|0|$ means that /o/ may or may not be used
}

Figure 10: IPA Table (Source: Longman Dictionary of English Language and Culture, London : Longman, 1992). 


\section{PHONOLOGY}

\subsection{INTRODUCTORY NOTE}

Phoneticians, starting from the neogrammarians (Junggrammatiker), $\mathrm{H}$. Paul (1846-1921), K. Brugmann (1849-1919), H. Osthoff (1847-1909), just to mention some of the leading figures of this group, opposed the theory of A. Schleicher (1821-67), who considered each language as a living organism and believed that there was no way to explain how speech really functioned. They main tained that a language is the collective product of groups of people whose linguistic practice followed strict rules. By contrast, the Russian phonologists, R. Jakobson and S. Karcevskij, two of the main members of the so-called Prague Circle, maintained most people express themselves in accordance with a well defined syntax, although they may not know its rules at a conscious level.

The same applies to phonological phenomena. At the end of the 1930 s, another Russian linguist, N. S. Trubeckoj (a leading member of the Prague Circle) and the American, L. Bloomfield, changed the pre-structuralist concept of phoneme as reported by Marouzeau in 1933. They saw it in phonological terms, as a sound marking the distinction in view of its meaning (e.g. van vs tan) to which it is worth comparing the theory of the 'distinctive traits' elaborated by Jakobson, G. Fant, and M. Halle in 1953. This shows a relationship between the material (physical) aspect of sounds and the psychic concepts to which they respond both from the speaker's and the interlocutor's vieupoint. With reference to that, it should not be forgotten that experimental phonetics has allowed to demonstrate that a difference of sound does not necessarily imply there is a difference of meaning for either the speaker or the receiver, just as there are not two identical sounds.

Every language is characterised by its unique phonological system, regulating the sound sequence with respect to certain limits which depend on the structure of the language itself. This is the very domain of phonology, the study of speech sounds, that is the pronunciation of whole sentences and the rules governing them where we cover the range of accents described, the analysis of corresponding sounds, the way they function together (units of Dhonology) and the symbols (morphemes) employed to describe them.

Without realising it, the speakers of a language exploit systematically certain phonological differences in order to enable themselves to communicate according to the establishment of pairings between pronunciations and meanings. Individual morphemes do play a key role in this scheme in which 
their individual phonological representation determines their corresponding pronunciations. It is easy to imagine that it would be impossible to communicate between us if all the morphemes of English were pronounced identically. Although it must be said there is no problem since there is only a very limited number of such morphemes, like sack $=$ dismiss and sack $=\mathrm{a}$ large bag, consisting of a sequence of four segments, that is their phonological representations which happen to be identical. But there are other examples where the distinction is produced by one segment only: /d/ and / $\mathrm{f} /$ as in $\mathrm{dig}$ and $f i g$, or $/ \mathrm{f} /$ and $/ \mathrm{v} / \mathrm{as}$ in fan/van or vat/fad. Then there are other cases where /c/ and /b/ as in come and bum, which, though consisting of four and three segments respectively, apart from having different ones only at the beginning (/c/ and /b/), for the rest sound exactly the same. Note that all that is governed by phonological rules which connect surface structures with their phonetic manifestations.

Before proceeding, it will be surely useful to familiarise with the world of phonology by introducing the following basic elements:

- phone is referred to any elementary speech sound (e.g. er, $\mathrm{mm}$ );

- phoneme (phōne = voice), as we have already seen in the previous section, is the smallest unit of speech, felt to be in any one language a variant of one sound that can be used to make a word different from another which is the same in every other way. For example $/ p /$ in 'pig' and /b/ in 'big' represent two distinct phonemes put conventionally between slashes / /; their difference depends on whether the vocal folds are vibrating while articulating them, thus conveying a different meaning. Similarly, sat, pat and tap, belonging to different semantic areas, are considered as phonologically identical except for their initial letter, an element that marks them as different lexical items. Incidentally, it must be said that linguists have not come to an agreement yet on what phonemes really are and how they can be found.

- allophone is another element of the sound system, a variation in sound of a phoneme indicating a phonetic difference, but not a phonological or phonemic one; it involves no meaning difference and is traditionally put between square brackets [ ]. For instance, allophones such as $[\mathrm{p}]$ sounds, depending on their position within a syllable, can be un-aspirated as in tap, or marked by a slight puff of breath (" $p h$ ') as in put which is clearly aspirated. These represent variants or allophones of $[\mathrm{p}]$ that can hardly be detected even by 
a native speaker since they do not convey any meaning. You may also consider $[\mathrm{k}]$ and $[\mathrm{t}]$ which have similar characteristics as $[\mathrm{p}]$. Yet for your knowledge, you should learn that by contrast, in most Chinese dialects and in some Northern Indian languages, the division between aspirated and un-aspirated consonants is phonemic or functional.

Unfortunately, since I cannot get you to hear what is being discussed, here is a chart showing how to articulate the different sounds by placing or moving the tongue or lips which I hope will help you to experience for yourselves what we are dealing with:

\begin{tabular}{|c|c|c|c|c|c|c|c|c|}
\hline $\begin{array}{l}\text { Passage } \\
\text { of air }\end{array}$ & $\begin{array}{l}\text { Vibration } \\
\text { of Vocal } \\
\text { Cords }\end{array}$ & $\begin{array}{l}\text { Two } \\
\text { Lips }\end{array}$ & $\begin{array}{l}\text { Lower } \\
\text { Lip. } \\
\text { Upper } \\
\text { Teeth }\end{array}$ & $\begin{array}{l}\text { Tip of } \\
\text { Tongue. } \\
\text { Upper } \\
\text { Teeth }\end{array}$ & $\begin{array}{l}\text { Tip of } \\
\text { Tongue- } \\
\text { Back } \\
\text { of } \\
\text { Upper } \\
\text { Teeth }\end{array}$ & $\begin{array}{l}\text { Front } \\
\text { of } \\
\text { Tongue } \\
\text { Front } \\
\text { of } \\
\text { Palate }\end{array}$ & $\begin{array}{l}\text { Back } \\
\text { of } \\
\text { Tongue. } \\
\text { Soft } \\
\text { Palate }\end{array}$ & $\begin{array}{l}\text { The } \\
\text { Vocal } \\
\text { Cords }\end{array}$ \\
\hline $\begin{array}{l}\text { Completely } \\
\text { stopped }\end{array}$ & $\begin{array}{l}\text { No- } \\
\text { Voiceless } \\
\text { Yes- } \\
\text { Voiced }\end{array}$ & b & & & t & & k & \\
\hline $\begin{array}{l}\text { Two sounds: } \\
\text { A stop } \\
\text { followed by } \\
\text { a continuant }\end{array}$ & $\begin{array}{l}\text { No- } \\
\text { Voiceless } \\
\text { Yes-- } \\
\text { Voiced }\end{array}$ & & & & & $\begin{array}{l}t \int \\
d 3\end{array}$ & & \\
\hline $\begin{array}{l}\text { Through } \\
\text { a narrow } \\
\text { opening }\end{array}$ & $\begin{array}{l}\text { No- } \\
\text { Voiceless } \\
\text { Yes- } \\
\text { Voiced }\end{array}$ & & f & $\begin{array}{l}\theta \\
0\end{array}$ & $z$ & J & & . \\
\hline
\end{tabular}

lïgure 11: Making the consonant sounds. (Source: The Functional Notional Approach by M. Fïnocchiaro and (.. Brumfit, ()xford: Oxford (Iniversity Press, 1983, 115)

The same point as above, can be made about those elements which can help to differentiate one word or sentence from another. See the following examples:

- The eagles soar high into the sky.

- The eagles saw high into the sky. 
There is no difference whether $/ r /$ is pronounced with the standard Southern British sound (non-rhotic), or with the typical Scottish roll (rhotic), since these are just phonetic variations. On the contrary, its presence or absence (e.g. soar vs sanv) results in a phonological difference because the $/ r /$ sound serves to mark the distinction between the two sentences. (For completeness' sake, I must recall here that in spoken speech, you may detect the so called intrusive $/ \mathrm{r}$ after a vowel sound such as in the second example above, reading 'so:r'.)

At this point, I would recommend that after practicing sounds in isolation or in minimal pair contrasts, students should use them in a communicative context because that is when they may change altogether. In fact, if we take into consideration vowels, we note that their quality changes, depending on whether they occur in stressed or unstressed syllables. For example, in "What do you do?" the first do bears a weak sound of the vowel, whereas the second contains a long stressed vowel form. Similarly, can, must, and some just to mention some of the most common items, generally speaking, have a weak form in questions ( $k a n$. mast, sam) and a strong one in most other kinds of sentences (kaxn, must,shm).

\subsection{UNITS OF PHONOLOGY}

Each human being has a very personal way of speaking, known as idiolect. However, what may sound even more extraordinary is that, according to some linguists, none of us makes the same group of speech movements twice in a lifetime. This very point links up with phonology which, by making abstractions from the physical sounds, can help us to see the relevant units of speech behind them: articulation, catenation, rbythm. (Intonation, including length and stress, will be dealt with in a separate section called "supra-segmental units".)

\subsubsection{ARTICULATION}

Even if the varieties of articulation are virtually uncountable, the number of phonemes or relevant units of articulation in any language is less than one hundred. But as just shown above, phonemes make the distinction from word to word possible, which does not mean that speech is a 'string' of isolated single phonemes, in contrast, it is a stream of sound regulated by units of liaison, stress, rhythm and intonation.

\subsubsection{CATENATION OR UNITS OF LIAISON}

Liaison concerns the gathering of phonemes in syllables (syllabification) and the grouping of syllables through junction/pause, assimilation, elision, and word-linking. 
- Syllabification is the way in which languages divide the flow of speech into syllables, which are a word or parts of a word containing a vowel, or a consonant acting as a vowel, as is the case with 'cup', consisting of one syllable (monosyllabic), 'window' of two syllables win- and dow (dysyllabic), while 'appetite' with its three syllables, appe-ti-te, is polysyllabic.

Each language allows only a limited number of combinations of its phonemes and does not tolerate the others (English for example has no initial consonant groups of four consonants, while those of three and two that are accepted are less than the possible number which could be combined). Moreover, it is worth remembering that languages differ also as far as the position of their phonemes go: $/ \mathrm{h} /, / \mathrm{n} /$ and $/ 3 /$ are found only at the beginning of a syllable.

And here is a piece of practical advice: if you ever start a new line and need to cut a word in English, a) try to avoid it; b) if you cannot, make sure that the parts you separate have either a lexical meaning and/or a grammatical function in themselves, e.g. friend-

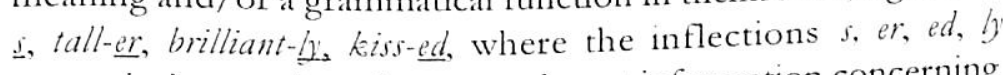
tespectively, encode and convey relevant information concerning number, quality and tense of the words they area added to.

- Junction

Junction helps to link syllables. In practice, it prevents the very same pronunciation of phrases like Give them aid and Give the maid. But if we look at the issue from a different angle, we may as well say that pause avoids the identical pronunciation as can be seen also in another example, I scream $=a i+$ skrim and $I_{i e}$ ream $=$ ais + krim .

\section{- Assimilation}

Assimilation occurs when some sounds undergo certain changes which are peculiar to that language, that is when a phoneme assumes features of a preceding or following phoneme. Take would you, which is often heard as [wudzju] where the /d/ of would combines with the $/ \mathrm{j} /$ of you to produce $/ \mathrm{d} 3 /$; or, don't you which people often utter as [dontchyu] where the / $t$ / of don't combines with the [j] of you to produce $\left[\mathrm{t} \int\right]$.

A second example is represented by the changing pronunciation of words ending in consonant clusters. Consequently, must is 
usually pronounced $[\mathrm{m} \Lambda \mathrm{st}]$ when on its own and when followed by words beginning with a vowel, but as [mus] before words beginning with a consonant:

must arrive $=[\mathrm{m} \Lambda \mathrm{s}$ arraiv $]$

must tell $=[\mathrm{m} \Lambda \mathrm{s}$ tell $]$

must say $=[\mathrm{m} \Lambda \mathrm{s}$ say $]$

must not $=[\mathrm{m} \Lambda \mathrm{s}$ not $]$

These examples show that a sound segment has different pronunciations depending on what segments are close to it in the string. For instance, the English $[\mathrm{k}]$ has a different pronunciation when it occurs at the beginning of a word such as car, uttered with a slight puff of air, while the $[\mathrm{k}]$ of skid, occurring after $[\mathrm{s}]$, does not have it. But if we get one step further and consider a sentence where both these words are employed, "I put the brakes on and the car went into a skid.", and try to see how its meaning and pronunciation are related, we find that the phonological representations of the morphemes making up the sentence do not define its pronunciation in all its phonetic details. Actually, you have to bear in mind that generally speaking languages are characterised by broad phonological principles which apply to all their morphemes and not to single ones, although these principles called phonological rules interact with the phonological representations of individual morphemes in order to determine the global and detailed pronunciation of a sentence.

- Elision

Elision is the dropping of a sound, which occurs when there are too many coming together; this happens especially when there is a consonant cluster. It varies just like the system of assimilation. In English, for instance, there is a tendency to drop the $/ t /$ in words like castle, listen, postman.

- Linking

Linking takes place when two vowels occur together (see diphthongs), English divides and links words mainly through glides $/ \mathrm{i} /$ and $/ \mathrm{w} /$, which are the sounds made while passing from one position of the speech organs to another:

You / w / often try to / w / escape. He / i/ always borrows my /i/anthology. 


\subsubsection{RHYTHM}

Each language is marked by its own rhythm characterising the regular occurrence in time of some particular phonological features. Languages can be distinguished between two categories: those called syllable-timed because of the regular occurrence of the syllable which determines the rhythm irrespective of stress (e.g. French and Italian), as opposed to those where stresses occur at regular intervals irrespective of the number of intervening unstressed syllables, which is the case with stress-timed languages like English, Russian and German. The latter is clearly shown by this example where to get the "message" through, a teacher may either use a metronome or beat the rhythm on a desk:

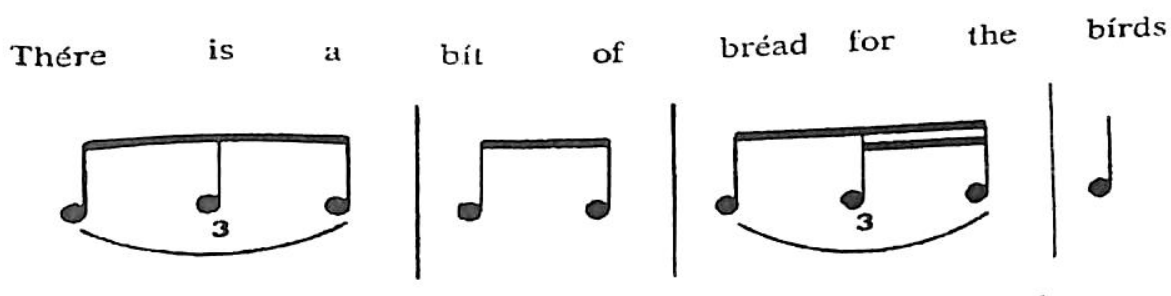

Fïgure 12: Rhythm. (Source: Corder S. Introducing Applied Linguistcs, Harmondsworth: Penguin, 1983, 254)

This demonstrates that each unit of rhythm, called foot, is affected by the stressed syllables in a sentence. The pitch and length of each syllable depends on how many syllables there are in the foot and on their importance. In other words, rhythm adjusts the length of vowels according to the situational context they happen to be uttered. By way of example, the vowel of glass is longer than the same sound in a glass of wine. Similarly, if we add an adjective (e.g. kind) to the sentence, Helen is a girl, we get Helen is a kind gir/ where we detect an acceleration in rhythm which continues like that if we add other adjectives to the original sentence, e.g. Helen is a kind and attractive girl. As a result, native speakers of English tend to keep the same time between one stressed syllable and the next, which often makes non-native speakers of English say that 'the English eat their words while speaking'. If we approach the issue in technical terms we can say that this shows that the unstressed syllables are uttered quickly, while the unstressed vowels are reduced to the symbol /a/, known as schwa, a vowel sounded typically in word parts spoken without stress as 'a' in about, since it has no regular alphabetic corresponding symbol. 
There is little wonder if rhythm is considered as one of those things which language learners, especially if they are over eleven and have not many opportunities to expose themselves to the language (e.g. watching TV, movies, listening to radio, recordings, etc.) have usually great difficulty in picking up correctly. Indeed, this is a problem resulting in distorted communication.

\section{SUPRASEGMENTAL UNITS}

So far we have treated only sound segments. Now we will spend a few words also on length, stress, and intonation. These are called suprasegmental phenomena because they are commonly written by marks put above the symbols indicating segments.

Variations in length and loudness are known as stress, whatever this means linguists have not agreed upon yet. In any case, here, we will try to make a distinction between these phonological entities.

\subsection{LENGTH}

Length implies that two vowels may be the same except for their duration. For instance, in bat and bad, the $/ a /$ is shorter in the former word, sounding [bæt] and [bæd] respectively. In general, English vowels are shorter before voiceless consonants and a little longer before voiced ones.

\subsection{STRESS}

Languages vary considerably in the rules for placing stress within words. Thus, some languages have very simple rules, e.g. French and Spanish, with the stress on the last and penultimate syllable of all words respectively; while stress in English has always been considered as unpredictable because it may shift from the last to the penultimate, antepenultimate and preantepenultimate syllables:

platoon [plo' tu:n] ; embody [im' bodi] ; humidity [hju:' mIditi] ; definitely ['definitli]

Yet the shifting of the accent is not so mysterious when it is used to add morphological information, in fact its position becomes predictable. Consequently, if we take the sample-words above, the differences among them are a function of the differences between their corresponding parts of speech, verb, noun and adverb, whereas the stress in platoon is due to the long vowel in that syllable (cf. Mal'tese $=$ mo:l'ti:z). 


\subsubsection{WORD-AND SENTENCE-STRESS}

In English there are two types of stress, word-and sentence-stress. It goes without saying that stress must be learned as part of the pronunciation of each word in isolation first, and then it should be practices in continuous speech in a variety of different sentence-stress positions.

- Word-stress may occur on any one syllable of a word, and cannot be changed by speakers as they may wish (except within an extremely limited number of situations). Certain linguists distinguish four levels of stress in English: $/ \%$ primary, $/ \wedge$ secondary, $/ /$ tertiary, $/ /$ weak (e.g. ópéràtór).

The kind of stress we are dealing with may be phonemic, producing a difference in meaning, as in 'contract (noun) and con'trait (verb), or else - as it is more often than not the case - it may be non-phonemic, having no meaning-significance (e.g. 'apple having first syllable stress as opposed to a'ppendix which is always stressed on the second syllable).

Moreover, stress varies with respect to English compounds. If we take, redhead, red is articulated with more emphasis than the second half of the word, while it is the opposite with red head.

- Sentence-stress shifts in the sentence according to the speaker's mood and attitude. Actually, in any sentence, one word is given more information prominence than the others, and this prominence is signalled by initiating a 'change of pitch direction' (a falling or a rising movement) on the stressed syllable (see section on Intonation below):

When do you leave for London? - focusing on the person

When do you leave for London? - focusing on the time

When do you leave for London? - focusing on where

When do you leave for London? - focusing on the action

Moreover, it will be interesting to note, in the examples below, that syllables get shorter in various languages, but in English in particular, as the length of a sentence increases, while the time intervening between the main sentence stresses tends to remain the same.

a. MAGgan's a WOman.

b.MAGgan's a wonderful WOman.

c. MAGgan's a very wonderful WOman. 
d.MAGgan's not a very wonderful Woman.

This is a good exercise to acquire the sense of rhythm and intonation that students can do on their own by checking the time needed to utter the different sentences.

\subsection{UNITS OF INTONATION}

When we hear somebody speaking, we notice that the tone of the voice is never flat, it goes up and down. This is called intonation and indicates the rise and fall in the level (pitib) of the voice in a sentence. In some tone languages, e.g. Chinese, Burmese, and Yoruba, a pitch feature distinguishes the meaning of words. (A practical example in Adangwe, a West African language, is represented by the word ma whose meaning changes according to the pattern used to utter it, so it may mean 'dough', 'herring', or 'nation'. In English and in most European languages, intonation is phonemic for it adds meaning to what is being said, as when you intend to show that the speaker is pleased, that a question is being asked, or you can say "yes" meaning "perhaps", "naturally", or even "no". If we consider the sentence:

Anna Maria has divorced ber busband.

By changing the intonation we can have a question, a statement, an angry exclamation, a sense of surprise, etc. Or further,

(a) Diana isn't singing tonight (but Edju is) vs (b) Diana isn't singing tonight (but tomorrow).

By stressing Diana, we indicate that someone else is singing (e.g. Peter), whereas by stressing tonight, we are indicating that Diana is singing some other time (e.g. tomorrow)
(c) Nick has programmes to leave
vs
(d) Nick has programmes to leave

In the first sentence, by applying the primary stress on "programmes", it results that Nick intends to leave certain programmes (i.e. before going away from his place of work), while in the second, by applying the primary stress on "to leave", we mean that Nick simply intends to go away from his place of work. The change in meaning depends on the syntax of the sentence, that is on leave being used transitively in (b) and intransitively in (d), which, to say it with Chomsky, is reflected at deep structure level but not at surface level. 
It is evident that intonation carries important information of an accentual, grammatical, syntactic, or attitudinal kind, and as a conveyer of meaning varies from area to area, person to person where variants depends on sex, mood, age, resulting in an unlimited number of differences. Hence, it is pretty obvious that to describe intonation we need designate units of intonation starting from those corresponding to relative differences in the way of speaking of each person, which in English correspond to the four tone phonemes as fixed by linguists such as Hill and Pike. Some of these pitch signals occur with the same meaning in many languages using intonation, but it is important for a learner to identify the English pitch patterns as they may differ deeply from those of his own language. English intonation has five moving tones, including the low fall (fall from mid to low), high fall (fall from high to low), low rise (rise from low to mid), high rise (rise from mid to high), fall-rise (fall with rise) which is heard comparatively rarely in most other languages.

Now, let's see how some of these tones are used in practice:

Falling-rising (from bigh to low $\searrow \nearrow$ ):

No or Yesterday (one word)

It doesn't matter (when there is more than one word and both of them have accentual prominence).

Besides serving to underline the accented words in an utterance, intonation may also distinguish different types of sentences and attitudes of the speaker, as shown in the following sentence-types where we use the risingfalling intonation $\nearrow$ :

- statements: You can play tonight.

- wh questions: Why don't you come?

commands, warnings: Don't smoke at home.

requests: Please, open the door.

exclamations and greetings: Good morning. How annoying!

attached/tag questions asking for confirmation: Helen is bere, isn't she?

Alternatively, in the sentences below we use a rising intonation $\nearrow$

Yes/No questions: Are you Italian? Yes, I am / No, I am not

Modals: Will you answer the phone? 
- Attached/tag questions asking for information: John isn't here, is be?

It is most noticeable that linguists have paid less attention to the creation of a standard notation for rhythm and intonation, especially if we compare it with the many symbols created for isolated speech sounds. Thus, what we have is the result of a personal notation system best fitting the individual linguist's work. This can be classified into three types:

a. Numerical, using numbers to indicate tone changes. This can be subdivided into:

the scale type based on an average total range of nine semitones; the level type assuming a certain number of levels which are numbered individually;

the frequency type is very accurate, but virtually difficult to use outside a laboratory, being based on number of variations in cycles per second indicated under each syllable.

b. Linear, using dots, dashes, curves, and musical notes to visualise the material to be analysed.

c. Accentual, using all sorts of accents (grave, acute, circumflex), arrows and dots. There are two kinds of accentual notation, beadnucleartype, that is the high tone of the first stressed syllable, and tonetic-stress type, distinguishing between static and kinetic tones. 


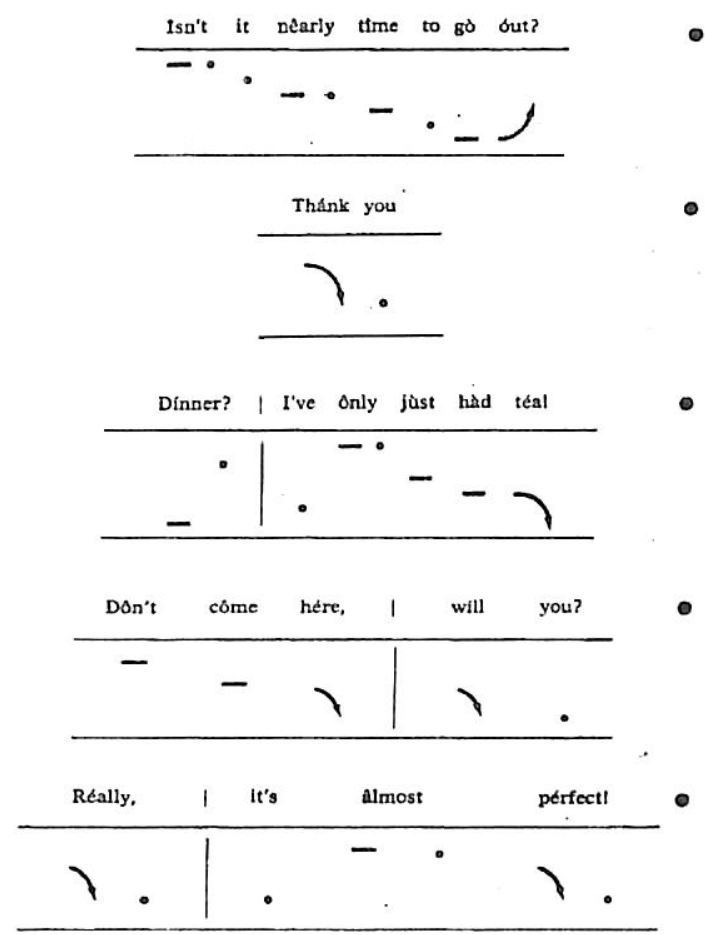

Figure 13: Examples of rising and falling intonation. (Source: Mackey, William F., Language Teaching Analysis, London: Longman, 1981, 58-59)

\section{MORPHOLOGY}

Morphology, a separate branch of phonology, deserves a separate section for its vital role in the structure of a language. It deals with the study of the morphemes of a language, that is the smallest bit of language that has its own meaning, either a word or part of a word: 'teacher' contains two morphemes - 'teach' and 'er'. Morphology studies the way morphemes are joined together to make words, and accounts for variations in their phonetic manifestations, such as certain changes which due to their regularity are considered to be part of the grammar or morphology, and are referred to as morphological.

For instance, the $/ \mathrm{s} /$ added to a noun to form the plural is pronounced: - $/-\mathrm{s} /, \mid-\mathrm{z} /$ or $/ \mathrm{iz} /$, depending on how it assimilates to the preceding sound. The choice to mark the plural is certainly not random; in fact, as illustraced by the following examples, it comes out in speech, as an - / / / in cup, cat, clock, cliff, cloth (ending with the voiceless phonemes: / p, t, k, f, $\theta /$ ), e.g. $\operatorname{cups}$ (cf. the $/ s /$ in the Italian $\operatorname{stanz} a$ ); as 
- /iz/ in dish, glass, clutch, judge, garage, fez (ending with $\int, \mathrm{s}, \mathrm{t} \int, \mathrm{d} 3, \mathrm{3}, \mathrm{z}$ ). For instance, see dishes where according to a phonetic rule the vowel [e] is inserted between the last segment of the noun and the suffix [s]; and as $-/ \mathrm{z} /$ (cf. the $/ \mathrm{s} /$ in zero) in all the remaining final sounds.

It is surely worth noting here that these different forms of the plural affix in English /-s, -iz, -z/, occur after voiceless, strident, and voiced consonants respectively, as a natural thing. In this sense, the second form is really most telling as it occurs whenever a strident consonant $/ \mathrm{z} /$ or $/ \mathrm{s} /$ would otherwise be next to the strident consonants listed above. Consequently, this shows that certain phenomena are predictable not only according to a phonological theory but also by reference to psychological and physical facts. These general phonological rules apply also to other phonological phenomena, the third person singular of the present indicative ending and the possessive morpheme.

But, within the area of morphology, one may quite legitimately wonder why there are also so many irregularities and ask why, for example, the plural of deer is deer, of foot is feet, or of child is children, and not deers, foots and childs respectively. Well, the explanation can be found in the history of English, when in Old English nouns used to have inflections, changing according to cases, just like Latin and present German. Therefore, the endings indicated also whether a word was singular or plural, in the nominative both singular and plural deer did not vary and was deor, whereas child was cild, children was cildru, and foot, feet were fot and fet.

Likewise, it is in the history of English, namely that of the Old English period (AD 500-1050) that we can find the reason why, for example, the past simple of give is not gived but gave. However, we can approach the issue also from the phonological point of view. We have to distinguish between absolutely irregular forms, characterised by phonological rules, which apply only to individual verbs like, give whose past simple and past participle forms are gave and given, clearly requiring a special rule, that is the use of certain morphemes, $/ a /$ instead of $/ i /$ and $/ n /$ to be added to give itself. It is not by mere chance then that learners of English find irregular verbs very hard to memorise. Yet, if you apply a rational approach it is possible to simplify and ease the task. If you take a positive attitude and instead of marking the differences among, you will notice that it is possible to divide them into coherent groups according to what they have in common. For example, there are those sharing the same change when conjugated in the past tense: blow, draw, fly, grow, know, throw, changing $[\mathrm{o}, \mathrm{a}, \mathrm{y}]$ into [e]; or bring, buy, catch, fight, seek, teach, and think, whose 
past tense and past participle is formed by substituting everything after the first morpheme with a/ought, except for bring and think which retain the [r] and $[\mathrm{h}]$, respectively. And, besides those verbs which do not change at all (e.g. $p u t,(u t$, or $(e t)$, and other possible categorisations, there are those groups of verbs which are quite consistent, such as begin, drink, ring, shrink, sing, sit, spit, spring, stink, and suim, which are put in the past tense by changing the vowel from [i] into [a], e.g. drank, and into the past participle by changing it into [u], e.g. drunk. We may then conclude that apparent morphological irregularities sometimes turn out to be regular forms in their own right, when considered in relation to the overall phonological system, and if we analyse them beneath the phonetic surface, where they show a difference which may result in an underlying uniformity, or regularity if you like.

It is worth noting that five-sixths of the 360 strong verbs have changed to the weak pattern. In various periods, you can find both forms, as is the case with of helped and holp in the the $16^{\text {th }}$ century. But what is even more interesting is the fact that all new verbs follow the $e d$ - weak ending today (e.g. xerox-ed, fax-ed). A final point worth making is represented by the inflection /-ed/ used to form the past simple and the past participle of regular verbs, but we do not always pronounce the $-d$ ending in the same way. So, verbs which end in the following sounds:

- $/ \mathrm{p} /, / \mathrm{s} /, / \mathrm{S} /, / \mathrm{f} /, / \mathrm{t} \int /, / \mathrm{k} /$ are pronounced / $/ \mathrm{t}$ (e.g. stopped, kissed, splashed, scuffed, laughed, reached, worked;

$-/ \mathrm{t} /$ and $/ \mathrm{d} /$ are pronounced /id/ (e.g. started and intended);

- all the other cases are pronounced $/ \mathrm{d} /$.

\section{CONCLUSION}

On ending this modest contribution to the study of the English language, I hope I have reached my aim: shedding some light on the nature of the speaking system itself from the point of view of phonetics and phonology. Two linguistic areas which are more often than not neglected, but which I think deserve all our attention since they can help students to improve their learning of a language if approached in a less detached way than they usually are. Needless to say that this work is not meant to bring forth any new element in the phonetics research field as such but it is simply meant to introduce the basic elements for students who intend to commence their study of one of the most complex areas in the linguistic field and make the study more appealing and involving. Therefore, I hope this paper will stimulate thought, direct attention and participation. 
Just before closing, I would just like to say I have relied upon published works in the field concerned and would willingly acknowledge my indebtedness for the information and enlightenment the authors of the books listed at the end of the article have provided.

\section{WORKS CITED AND SUGGESTED READINGS}

Brazil D., M. Coulthard, C. Jones. Discourse Intonation and Language Teaching. London: Longman, 1980.

Catford J. C. A Practical Introduction to Phonetics (Oxford Textbooks in Linguistics). Oxford: Oxford University Press, 2002.

Corder, S. Pit. Introducing Applied Linguistics, Harmondsworth: Penguin Books, 1983.

Dresher, B. E. 'Abstractness and Explanation in Linguistics', in Explanation in Linguistics, eds, Hornstein N., Lightfoot D. (eds), London: Longman, 1981.

Edwards H. T. Applied Phonetics (Singular Textbook). 2003.

Gimson, A. C. A Practical Course of English Pronunciation. London: Edward Arnold, 1981.

Hook R., and J. Rowell. A Handbook of English Pronunciation. London: Edward Arnold, 1982.

Ladefoged P. A Course in Phonetics (with CD Rom). 2005.

Langacker, R. W. Language and Its Structure. New York: Harbord, Brace \& World, 1967.

Lyons, J. Introduction to Theoretical Linguistics. Cambridge: CUP, 1979.

Newmark, J. Grammatical Theory and the Teaching of English. 1964.

Roach P. English Phonetics and Phonology Audio CD. Cambridge: Cambridge University Press, 2002.

Robins, R. H. General Linguistics Survey. London: Longman. 1976.

Small L. H. Fundamentals of Phonetics: A Practical Guide for Students. 2004.

Stockwell, R. \& D. Minkova. English Words. Cambridge: Cambridge University Press, 2001. 
Strevens, P. Nen Orientations in the Teaching of English. Oxford: Oxford University Press,1978.

Trudgill, Peter. Accent, Dialect and the School. London: Edward Arnold, 1978.

William. F. Mackey. Language Teacbing Analysis. London: Longman, 1981.

Yule, G. Pragmatics. Oxford: Oxford University Press, reprint 2003.

Handbook of the International Phonetic Association: A Guide to the Use of the International Phonetic Alphabet. International Phonetics Association, 1999. 